\title{
Integrative CAE-Driven Design Process in the Embodiment Design Phase of L7e Vehicle Structures
}

\author{
Roman Pawel Jedrzejczyk ${ }^{1, *}$ - Michael Sigmar Alb ${ }^{1,2}$ - Thomas Jost ${ }^{1}$ \\ 1 Virtual Vehicle Research Center, Austria \\ 2 University of Padova, Italia
}

\begin{abstract}
In the past decade, the mechanical engineering industry has searched for a design methodology that could systematically unify the support of computer-aided engineering (CAE) tools for the design process. More recently, some propositions have been put forward for the CAE-driven design process $(C D D P)$, but the efficiency of these design processes is questionable. We have proposed improvements and new arrangements that result in the integrative CDDP (ICDDP), which makes CDDP more reliable, efficient and predictive. The ICDDP redefines the role of CAE tools and positions the optimization technology as a fundamental driving force behind the whole design process. Consequently, the ICDDP orders design phases as: (1) conceptual design, (2) design crystallization and (3) design sophistication, which steer the design process sequentially. The accurately established linkages between the sequential design steps enhance the smooth recurrence of the ICDDP for new product executions. In addition, this work demonstrates the application of the conceptual design phase to design a new L7e (eQuad) vehicle structure. This phase of the ICDDP illustrates the specific steering methodology for the topology optimization of a new eQuad structure as well as the geometric solution derivation step that reveals the transformation of bionic shapes into rough manufacturable geometry. Additionally, the numerical verification of the simple geometric model is presented for the load cases given. Our results exemplify the fact that the ICDDP allows engineers to design new innovative and lightweight structures.

Keywords: CAE-driven design, L7e vehicle structure, conceptual design, topology optimization, lightweight design, geometric solution derivation

Highlights

- A design process that applies the concept of CAE-driven design is presented for new lightweight structures.

- The explanation of optimization technologies that depicts the driving force behind CAE-driven design.

- One of the first applications of the Integrative CAE-driven design process is proved for the embodiment design phase of the $L 7$ e vehicle structure.
\end{abstract}

\section{INTRODUCTION}

Over the last years, the idea of a simulation-driven design process has emerged [1]. The simulation-driven design process also includes the computer-aided engineering (CAE)-driven design process (CDDP). The CDDP offers a combination of simulation tools along with an adoptable and systematic approach to the design process. This combination enhances the possibility of applying as many simulation tools as necessary and enables designers to take advantage of reliable simulation methods. Sellgren [1] postulated that in major steps of the design process, computerbased modelling and simulations could support and provide the necessary information to reduce the working time.

Engineers and designers can profit from the CDDP by tailoring the design process to their needs. However, the broad definition of design sequence steps for a design process is usually poor and generic and only insufficiently link the design steps within the entire process. As a result, there are many examples of CDDPs that attempt to concretize the meaning of the CDDP idea but do so in different ways [2] to [4]. Some efforts focus on the application of numerous simulation tools; others search for solutions in a combination of optimization technology with different simulation environments. Moreover, existing examples are quite incomplete regarding a whole design process. These examples of existing CDDPs only cover a part of the design process, thereby reducing their usefulness for engineers and designers.

While CDDPs may allow for a considerable time reduction in the development process, unintegrated CDDPs need to be rearranged whenever the development of a new product or item takes place [5]. As a result, an additional amount of working time is required for the ad-hoc planning of suitable design processes. Such unintegrated CDDPs aggravate the risks of introducing inadequate design steps for the development of new products that can have fatal financial consequences for the project budget.

The development of modern lightweight items or structures often demands the application of many different CAE tools. Generic CDDPs enable engineers to combine several simulation and optimization tools from different suppliers within one CDDP. On the other hand, such combinations frequently result in the 
unintended regeneration of data exchange interfaces because of deviation in the data exchange process [6]. The revisions of interfaces can easily happen if new applications of well-known design solutions occur. Every time a new assemblage of the design tools takes place, it reduces the predictability of the design process. Moreover, several types of simulation and optimization tools increase the cost of the design process that includes additional expenses for new licenses and maintenance of simulation software, user training, etc. The licensing and maintaining of CAE software can cost considerably more than required for hardware [7]. In addition, the cost of training for the inexperienced or unfamiliar users of CAE software also remains high. The costs of user training add to the expenses of extra working time [8].

In this paper, we define the design process that employs the OptiStruct ${ }^{\circledR}$ software from the Altair ${ }^{\circledR}$ company, which links the existing tools in a specific way. The OptiStruct ${ }^{\circledR}$ software provides a variety of simulation and optimization tools for CAE applications. In this paper, we define repeatable linkages to the CDDP and the sequence of design steps to allow generalizations about the whole design process in other applications. Furthermore, we show the impact of our integrative CDDP (ICDDP) that demonstrates how the ICDDP can be implemented in structure design to fulfills its promises.

Additionally, we describe the first part of this ICDDP for topology optimization in the early embodiment design phase. Utilizing a real use case for the structure of the L7e vehicle class, we illustrate the universal character of our ICDDP that is suitable not only for automotive applications, but can be employed in many different fields of mechanical engineering such as rail, aerospace, and light and heavy machinery. The real use case of the L7e vehicle class exploits the reusable nature of the ICDDP because of the highly demanding nature of design processes in the automotive industry.

\section{INTEGRATIVE CAE-DRIVEN DESIGN PROCESS}

\subsection{Deriving Requirements for the ICDDP}

The CDDP is expected to improve the design process efficiency of new items and products, time and cost reduction. In consequence, different modelling and simulation types, such as computer-aided design (CAD), CAE, the finite element method (FEM) and computational fluid dynamics (CFD), need to be joined within one simulation environment [9]. Virtual methodologies, which are the foundation of the CDDP, magnify the possibility of recognizing and avoiding errors and mistakes during the design process, thus helping to create innovative products [6]. The CDDP allows for systematic and ordered project structures that reduce project costs, and time-to-market as well as ensuring the achievement of project goals.

Modern consumer goods, such as passenger vehicles, compete with each other for low final prices with many potential buyers. Nevertheless, extensive requirements in legal, technological, environmental, aesthetical (styling) and disposal areas complicate the design process. A new vehicle, for instance, should satisfy the occupant safety regulations [10] and [11] while allowing for reduced energy consumption [12] and [13]. Such requirements often invite competing solutions. Increases in occupant safety demand a tougher structure, which leads directly to an increase in vehicle mass. But the reduction in vehicle energy consumption can be realized mostly through mass reduction. Additionally, the shapes of the new vehicle body-in-white parts such as swooping rooflines, wheel covers and housings, extra front and rear spoilers, and rear wings, have a significant impact on the aerodynamic drag, which plays a crucial role in the development of energy-efficient commuter and premium luxury vehicles as well as track-oriented sports cars [14]. The lightweight body-in-white constructions frequently utilize a mix of various material types, which results in advanced joining technology such as adhesive bonding, rivets and blind-rivet joints, yet the fatigue life estimation is complicated for these types of connections [15]. To match these divergent demands, the optimization process should be applied during design and development [16]. Using different optimization methods, optimal solutions can be found for specific sets of requirements for example for structure design, noise, vibration and harshness, as well as suspension design in the new vehicle development process.

Consequently, Sjödin [2] presented the idea that multi-disciplinary optimization together with $\mathrm{CAE}$ methodology can support the design process. This approach enables the optimization of various subproblems in the vehicle development by applying many simulation and optimization tools whenever they are necessary. Moreover, the application of the CDDP is defined overly widely. In consequence, the linkages between the steps of the CDDP are unclear and mostly insufficient.

Compared to Sjödin's idea, Konzelmann et al. [3] and Münster and Schäffer [4] considered the early design phase and arrangement of design steps for the development process. In this case, the CDDP is a 
part of the vehicle development process that involves many small and different design processes. As a result, the linkages of the design steps and operations are defined freely, which can raise design uncertainty during project executions. Additionally, the widely defined backbone of the CDDP and an extensive range of different software and tools amplify a risk of the process interfaces' regeneration.

In recent years, the duration of automotive development cycles has been significantly reduced [17]. For this reason, the industry [18] and [19] requires a simple and universal methodology for the CDDP that easily adapts to specific industrial conditions and needs.

If the CDDP is defined and executed in a correct manner, it can fulfills the promises made. To obtain the full advantages of the CDDP, it is necessary to analyse the following questions first:

- What is needed for the CDDP to guarantee its unquestioned efficiency?

- How should the CDDP be defined to obtain a new lightweight structure?

- What should the first step of the CDDP be to design a new structure from scratch?

The next section of this paper provides the answers to these questions.

\subsection{Description of the ICDDP}

A frequently used approach for the design process of new structures is based on the VDI 2221-2223 Guidelines [20] to [22]. This approach utilizes the following four steps for the product development phase:

1. planning and task clarification,

2. conceptual design,

3. embodiment design, and

4. detail design.

These four steps represent a necessary effort for investment in a new product [5]. The planning and task clarification (Step 1) and conceptual design (Step 2) are relatively inexpensive compared to the embodiment design (Step 3) and detail design steps (Step 4) [23] and [24]. The effort of the two last development steps requires smart and innovative methodology.

The main idea of the ICDDP is based on the analysis of the current development processes for a new structure. This analysis identified three fundamental engineering areas:

- design (construction and manufacturing rules),

- simulation, and

- optimization.
The design constitutes the development process that applies the design principles including material selections, the way of construction, production costs etc., whereas the simulation (FEM, CFD, etc.) offers various methods for virtual analysis. Optimization technology matches the different opposing requirements and is the driving force of the ICDDP behind the whole development. Impulses to generate new ideas or review current ones result from the iterative nature of the optimization methodology. Therefore, the optimization technology becomes the driving force behind the ICDDP, depicted in Fig. 1.

The critical innovations, which the ICDDP brings to the whole design process with the optimization technology as a driving force, are the design operations sequences.

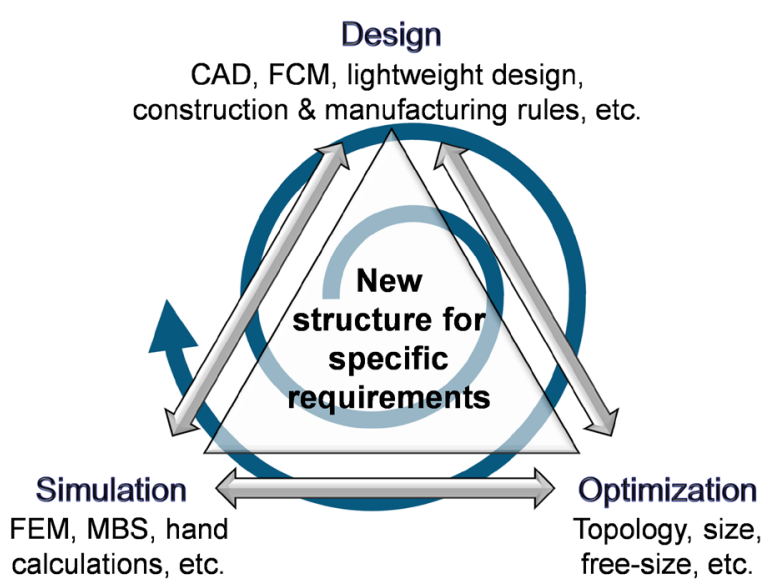

Fig. 1. Optimization as a driving force behind the ICDDP

In addition, the requirements and specifications, as well as the assessment of the current structure state (if available), should be available at the beginning of the development process [20]. This information helps to model the non-design areas, technological openings, and types of acting loads. Fig. 2 depicts the development steps of the ICDDP. The ICDDP is divided into three main phases: 1) conceptual design, 2) design crystallization, and 3) design sophistication.

The conceptual design phase starts the ICDDP and consists of two development steps: design space definition and model building, which are also the steps of a topology optimization (TO). The design space definition sets the boundaries for an available space for material utilization and defines rough geometric contours of new structures. In the model-building step, a simulation model containing the load case definitions is established and surrogate load cases, which consider the requirements for a new structure, can be defined. The design space definition and 
model building steps follow sets of technical and nontechnical specifications for a new structure that results in an FE model for the TO. The link between the conceptual design and design crystallization phases is the geometric solution derivation. This step allows engineers to transform the bionic shapes from the TO into simple engineering-based geometric elements, such as beams (profiles) and plates. The geometric solution derivation offers the opportunity to interpret the TO results precisely.

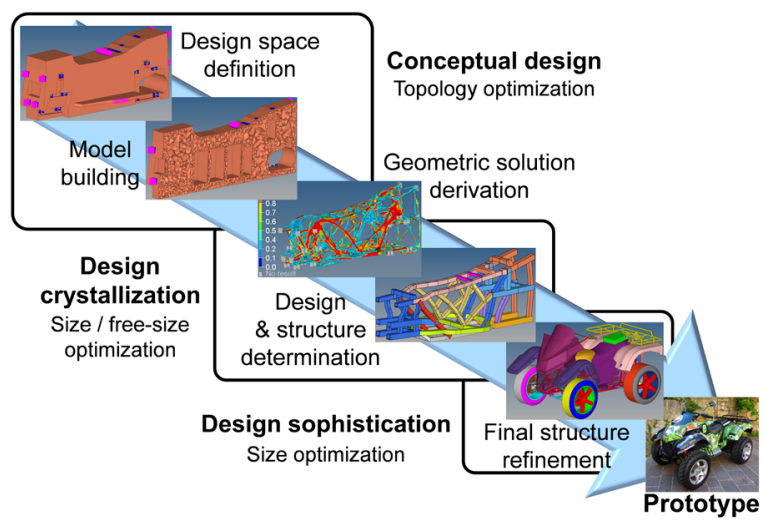

Fig. 2. ICDDP - steps and main development phases

The first draft design, which consists of beams and plates, takes shape in the design crystallization phase. During this phase, the size / free-size optimization methods permit engineers to discuss structure body-in-white types that crystallize the design of a new structure together with an analysis of different materials such as isotropic and orthotropic.
The discussion of structure body-in-white types, which allows for the customization of a new structure, enables design proposals to be formulated. We are carrying out the ongoing scientific investigation of this topic.

More importantly, this step of the design crystallization phase determines the structure body-inwhite types, material types for fundamental members (profiles and plates) and production (assembly) methods. Accordingly, the design sophistication phase strengthens a final structure refinement. In this stage, the size optimization enhances a new structure that arises in the second step as a combination of the best solutions for a specific given value of max stress, strain, etc. This enhancement involves sizing for the dimensions of profiles and plates. As a result, the ICDDP ultimately provides a new structure: a prototype for given sets of requirements and specifications.

Fig. 3 illustrates the design principles and approaches throughout the steps and main development phases of the ICDDP. For each design sequence in the ICDDP, Fig. 3 presents the necessary inputs, design actions and tools (including optional tools) as well as objectives that shape a new structure design incrementally and efficiently. These design sequences of the ICDDP utilize only one simulation software package (Altair OptiStruct ${ }^{\circledR}$ ) that provides the essential optimization and simulation methods. It is possible to integrate other software types into the ICDDP if they are necessary. In contrast, the result of one software application ensures that the interfaces

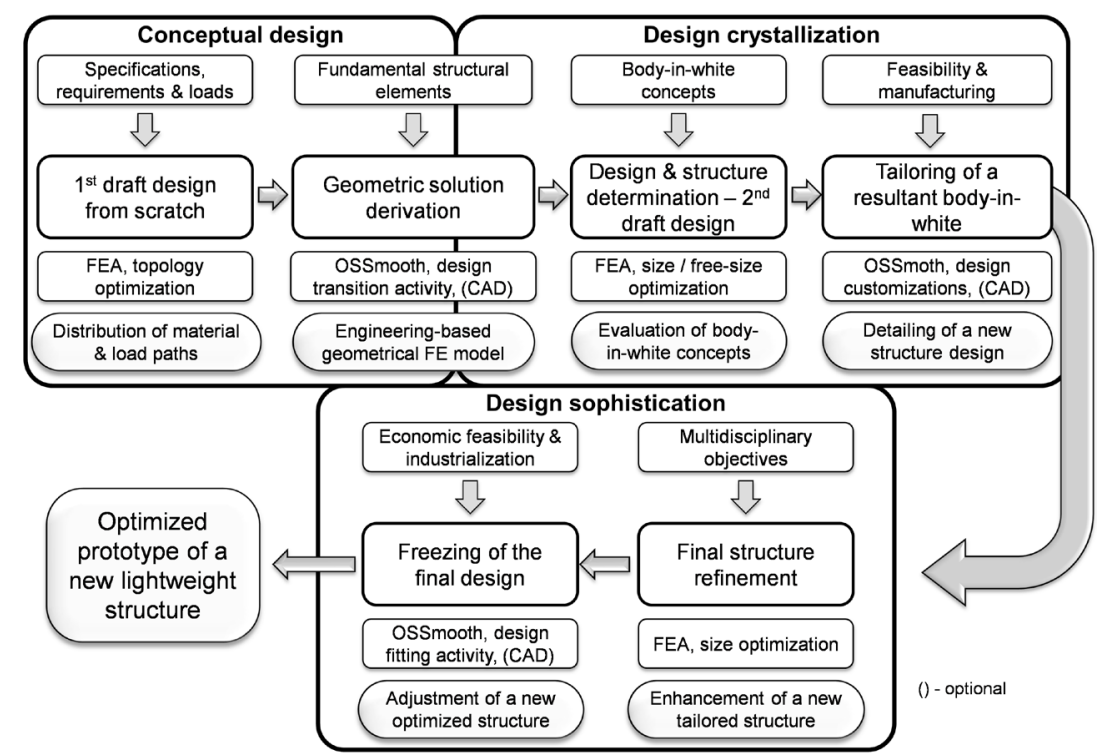

Fig. 3. ICDDP - design principles and approaches throughout the steps and main development phases 
of the ICDDP remain the same in each step of the ICDDP. Furthermore, for the simulation software, neither additional knowledge nor special user training is required.

The main steps and design phases of the ICDDP are universal and to perform them, the other software types that make essential simulation and optimization methods available (either partially or all within one software environment) can also be applied. The ICDDP reduces the iterative design actions of a product's development such as design and calculation loops that are continuously repeated during the execution of the classic approach to product development. This removal of the recursive design actions decreases the duration of the development cycles considerably. The reduction in the development time depends on the complexity and technological advancement of a new product. Smaller reductions are expected for a single part design compared to greater reductions for the full vehicle development, which involves the design of many different modules and parts.

The ICDDP demonstrates the advantages of the conceptual design and design crystallization phases where the direct design from scratch delivers the new functional design proposals without iterative and timeconsuming improvements in old designs. The ICDDP helps develop mechanical structures with different levels of complexity, i.e. body-in-white, brackets, hinges and crash boxes. More importantly, compared to the classic design approach, the ICDDP, with its more effective lightweight design (Fig. 18, section 3.2.3), provides new structures that meet specific sets of different requirements.

Altair ${ }^{\circledR}$ company provided an arrangement of optimization steps for the CDDP [25], which utilizes the same simulation OptiStruct ${ }^{\circledR}$ software and divides the design process into three major steps: conceptual design, embodiment design, and detail structure design. Additionally, the authors of this paper have already published the backgrounds for the ICDDP with the optimization technology before [26] to [28]. Because of the same calculation and optimization software, analogous similarities are possible in the arrangement of the design process between these two concepts.

We tested the conceptual design phase of the ICDDP by utilizing the TO for a new all-terrain L7e class vehicle (ATV) structure. In consequence, this application raised the following questions:

- How should the TO be performed to produce the universal and optimal material distribution for the embodiment design?
- Is it possible to generalize the TO results from one material type to another?

- Is it possible to use the intensity of material distribution from the TO of isotropic material for the composite material application in the embodiment design phase?

- How can the results of the TO be interpreted for the first draft design of a new structure?

- Do the crash loads influence the form and geometry of the TO results?

The following sections provide the answers to the present questions.

\section{CONCEPTUAL DESIGN PHASE OF THE ICDDP}

The ICDDP allows for innovative solutions in the early design stage. The conceptual design is the first phase of the ICDDP and utilizes the TO to establish a rough design. This rough design is far from perfection, but bionic shapes of the TO results contain useful pieces of information about material intensity and distribution. The TO application must follow an efficient and reliable methodology that takes advantage of solutions arrived at and reveals as many design suggestions as possible.

Fig. 4 shows the organization of the two next sections of this paper that display the efficient and reliable methodology for the TO as well as the TO results.

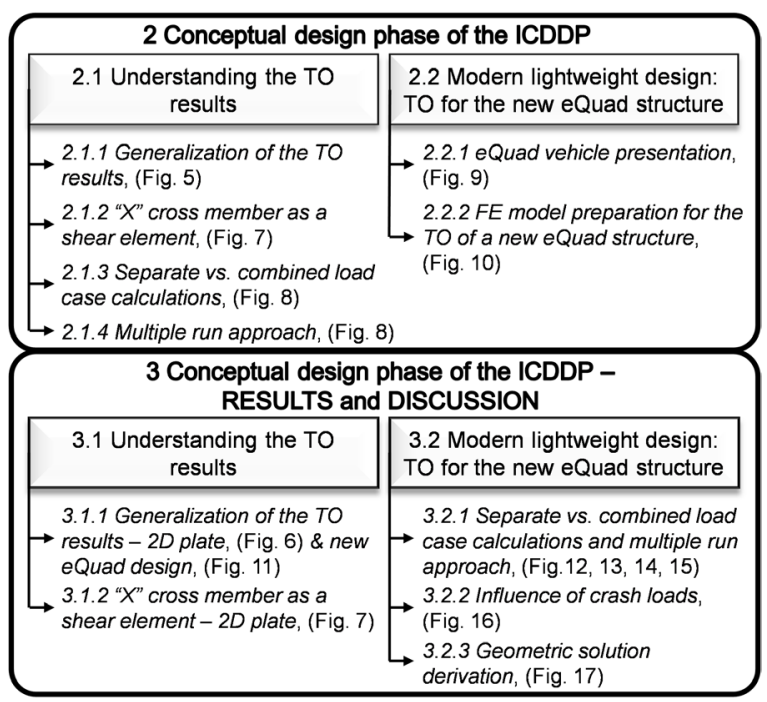

Fig. 4. Arrangement of the sections in the method and results and discussion

This organization helps indicate the advantages of the first ICDDP design phase and the resulting design of the new eQuad structure. Section 2 reveals 
the applied methodology, whereas Section 3 details the simulation results for the examples and real use case from Section 2.

\subsection{Understanding the TO Results}

Engineers and designers actively search for the application of different materials that enable them to design lightweight structures. To take advantage of new design proposals provided by the TO, engineers need to understand the pieces of information and new design proposals that the TO delivers. This section demonstrates the methodology of the TO and enables better understanding of the TO results.

\subsubsection{Generalization of the TO Results}

The studies of many different material types can result in additional product development costs. For this reason, the authors of this paper considered the generalization of the TO results that employs the results of one material to prepare the design for the structure of another material. This idea also exploited the structure compliance (or weighted compliance) [16], [29], and [30], which was the function to minimize throughout this paper. If the generalization of the TO results works properly, it can significantly reduce the amount of working time during the early design stage and provide a great design.

The authors of this paper investigated the generalization by applying the TO to a thin plate made of five different material types: steel, titanium, aluminum, quasi-isotropic carbon fiber reinforced plastic and orthotropic CFRP. Table 1 reports the material properties selected for the FE models of the TO and shows the values for the single woven and uni-directional ply of CFRP material, respectively [31] and [32].

Table 1. TO of the thin plate - material properties and resultant $Y$ displacements

\begin{tabular}{lcccc}
\hline Material & $\rho\left[\mathrm{kg} / \mathrm{mm}^{3}\right]$ & $E[\mathrm{GPa}]$ & $v[-]$ & $Y$ displ $[\mathrm{mm}]$ \\
\hline Steel & $7.85 \mathrm{e}-06$ & 210.0 & 0.30 & -0.122 \\
\hline Titanium & $4.40 \mathrm{e}-06$ & 115.0 & 0.33 & -0.222 \\
\hline Aluminum & $2.70 \mathrm{e}-06$ & 70.0 & 0.33 & -0.366 \\
\hline Q-I CFRP & $1.60 \mathrm{e}-06$ & $78.0 / 78.0$ & $0.06 / 6.5$ & -0.410 \\
\hline C-P CFRP & $1.60 \mathrm{e}-06$ & $126.0 / 11.0$ & $0.28 / 6.6$ & -0.410 \\
\hline Q-I - quasi-isotropic laminate, C-L - Cross-ply laminate \\
\hline \multicolumn{5}{l}{}
\end{tabular}

We utilized the HyperLaminate ${ }^{\circledR}$ software from Altair ${ }^{\circledR}$ to prepare the quasi-isotropic and cross-ply CFRP laminates. Fig. 5a depicts the thin plate under the constant load F; the total amount was $1 \mathrm{kN}$, and the principal dimensions: length and width were $3 a$ and $a$, where $a$ is $150 \mathrm{~mm}$, respectively. The volume (mass) during the TO runs of the generalization was constrained at $30 \%$ of the initial value. Additionally, the option HOMO was applied for the DTPL card to consider the homogenized material properties [29] and [30] of defined laminates during the TO runs.

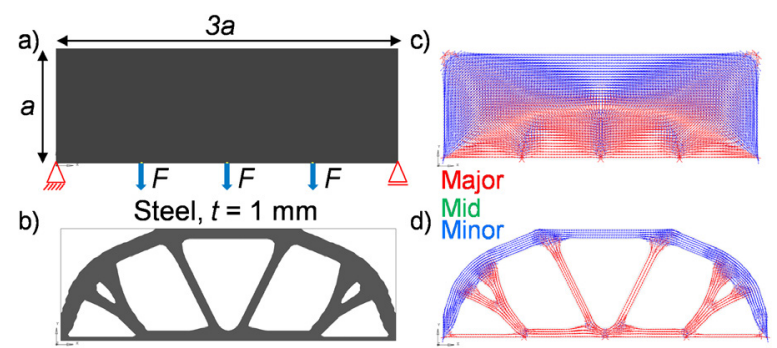

Fig. 5. Generalization of the TO results: a) FE model, b) results for steel ( $t=1 \mathrm{~mm}), c$ ) original shape tensor plot (stress), d) optimized shape tensor plot (stress)

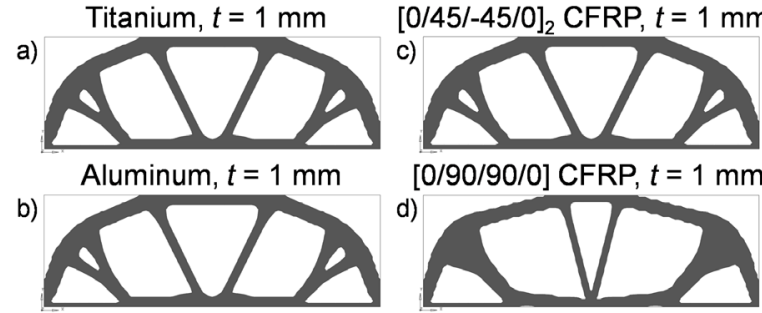

Fig. 6. Results of the plate's TO: a) titanium, b) aluminum, c) quasi-isotropic CFRP, d) cross-ply CFRP

\subsection{2 " $\mathrm{X"} \mathrm{Cross} \mathrm{Member} \mathrm{as} \mathrm{a} \mathrm{Shear} \mathrm{Element}$}

The TO frequently produces bionic shapes in which the elementary geometric forms, such as rods and plates, dominate. These fundamental geometric elements often form " $\mathrm{X}$ " cross-members. These members can be thicker or thinner (Fig. $7 \mathrm{c}$ to d) depending on the real case in the local material distribution, but the main geometric shapes remain easy to recognize. The current paper's authors examined the formulation of the "X" cross-members as an effect of the local presence of shear loads. For this purpose, the authors studied the thin rectangular plate (Fig. 7a) with the length $a=100 \mathrm{~mm}$ and thickness $\mathrm{t}$ made of steel (material properties are listed in Table 1) under the constant shear load $F$, where the total amount was $1 \mathrm{kN}$. The volume fraction $V F$ was limited to two different levels: 0.45 and 0.10 . 


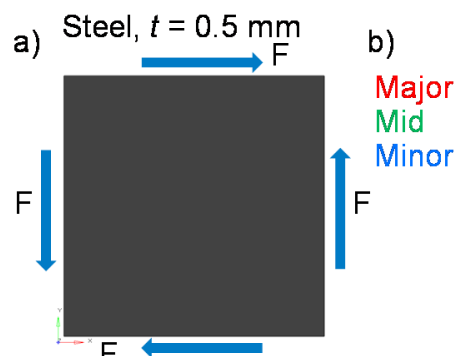

c)

$F_{V F}=0.45$

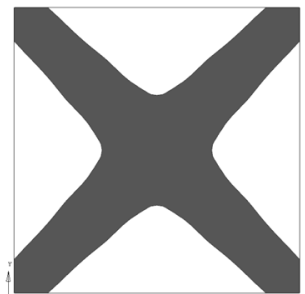

Whole plate

d)

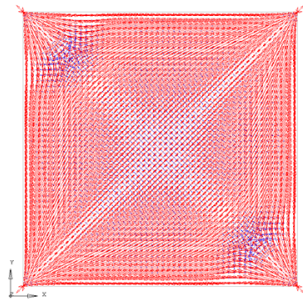

$V F=0.10$

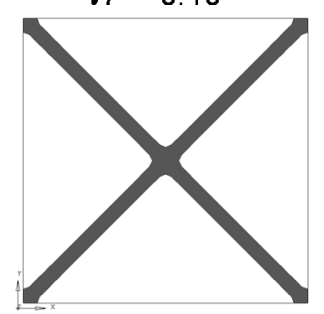

Fig. 7. TO of the shear plate: a) FE model for steel, $t=0.5 \mathrm{~mm}$, b) original shape tensor plot (stress), c) " $X$ " shape results at VF = $0.45, d)$ " $X$ " shape results at $V F=0.10$

\subsubsection{Separate vs Combined Load Case Calculations}

For mixed load scenarios, the TO results usually exhibit complex bionic shapes that intensify the difficulty to perform the design crystallization phase. Therefore, the authors of this paper performed an assessment of load case influences for separate and combined load cases. This assessment was based on the observation that a single separate load case reveals the bionic shapes more precisely. Instead, the combined load cases, which is a combination of single separate loads, can reduce and obscure the material and load path distributions due to a resultant character of combined loads. Consequently, a result interpretation is highly complicated for the combined load cases.

Fig. 8a demonstrates a proposal for the assessment of load case influences.
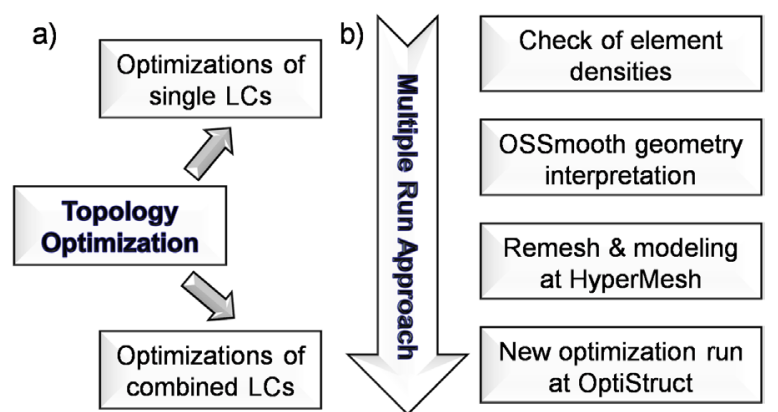

Fig. 8. Methodology of the TO: a) assessment of load case influences, b) multiple run approach

The method splits the TO process into the single and combined optimization runs. In this way, the bionic geometric shapes which delivered the TO for single and combined loads have an explanation for their presence. This explanation noticeably improves the interpretation of the TO results.

\subsubsection{Multiple Run Approach}

The TO results can demonstrate indistinctive character for a large and complex application (i.e. vehicle body structures), making the precise derivation of geometric solutions impossible. For this reason, the present paper's authors investigated a multiple run of the TO. The multiple TO run originated from Norberg and Lövgren's concept [33] and proposed running the TO for a given set of loads multiple times.

In contrast to Norberg and Lövgren's idea, we suggested that the multiple runs of the TO be performed with no additional control of the structure compliance. Instead, we performed the TO with a soft constraint on a resultant displacement, which is characteristic of the given set of loads. This soft constraint was not implemented into an FE TO model and can be based on user knowledge and experience, offering engineers the option of selecting the values of constraints arbitrarily. Fig. 8b demonstrates the idea of the multiple run approach. The method starts with the analysis of element density plots from the previous optimization run. The geometry interpretation is performed after the control of element densities. The OSSmooth ${ }^{\circledR}$ software within the HyperMesh ${ }^{\circledR}$ environment delivers new geometry for a specific density threshold. The meshing process is realized in HyperMesh ${ }^{\circledR}$ and the new model generated has the same boundary conditions as the starting model. The new OptiStruct ${ }^{\circledR}$ optimization run closes the loop of the multiple run approach. This loop can be repeated as many times as required. The main advantage of this method is to keep the amount of calculation time to acceptable levels. Applying this multiple run approach, the need for power and time computation increment gradually. If the method is applied, the load paths of new structures contrast more precisely.

Both present methodologies (assessment of load case influences and multiple run approach) can be applied either together for the TO, which was tested in this work, or separately, depending on the requirements. 


\subsection{Modern Lightweight Design: TO for the New eQuad Structure}

The ICDDP enables engineers to develop a modern lightweight structure that satisfies specific sets of technical requirements. The paper's authors carried out the conceptual design phase of the ICDDP for a new eQuad structure by applying the TO. The main objective was to obtain the distribution of material and densities as well as load paths through the available three-dimensional (3D) design space.

\subsection{1 eQuad Vehicle Presentation}

The eQuad is an alternative, powered quadricycle, which the VIRTUAL VEHICLE Research Center adopted and further developed into a full electric specification. The lithium-ion batteries provide the electric energy to the electric engine [34]. The research center modified the original structure of the eQuad tubular space frame (Fig. 9b) by utilizing the conversion design approach because of the packaging purpose of electric powertrain components.

The vehicle is classified as an L7e vehicle [35]. The maximal speed is $45 \mathrm{~km} / \mathrm{h}$, and it can travel 30 $\mathrm{km}$. The maximal permissible laden weight is $550 \mathrm{~kg}$, which includes two occupants and some luggage; the mass of the vehicle tubular space frame is $82 \mathrm{~kg}$.

a)

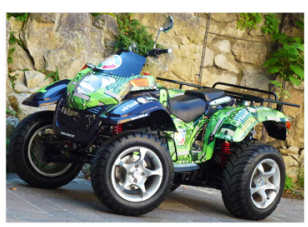

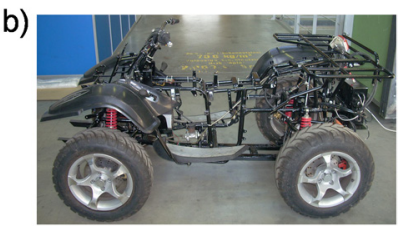

Fig. 9. Fully electric vehicle - eQuad: a) complete vehicle, b) tubular space frame

\subsubsection{FE Model Preparation for the TO of the New eQuad Structure}

Following the recommendation from [36], we defined the 13 different load scenarios for this work. These loads consider the various conditions: static, driving and crash situations. The load cases contain the forces for: vertical bending, front and rear torsion, front and rear braking, cornering, front and rear vertical bumps, bending for front and rear axles, and equivalent static front, rear and side crashes.

The estimation of the forces and load cases based on an approach of first-order models [37]. This approach enables engineers to execute instant analyses for what-if questions during the early design phase. We developed the additional equations for the first-order models that define the forces for the shortlong-arm suspension type under driving conditions.

Table 2. Load cases for the TO of the eQuad structure

\begin{tabular}{|c|c|c|}
\hline Load case & Calculation method & Dynamic coefficient \\
\hline Bending & FEM & - \\
\hline Torsion front & FEM & - \\
\hline Torsion rear & FEM & - \\
\hline Braking & 1 st $0 \mathrm{M}\left({ }^{\star}\right)$ & $\mathrm{Y}$ \\
\hline Braking into rear & 1 st $\mathrm{OM}\left({ }^{*}\right)$ & $\mathrm{Y}$ \\
\hline Cornering & 1st $\mathrm{OM}\left({ }^{*}\right)$ & Y \\
\hline Vertical bump front & 1 st $0 \mathrm{M}$ & $\mathrm{Y}$ \\
\hline Vertical bump rear & 1 st OM & $\mathrm{Y}$ \\
\hline Bending front axle & 1 st $0 \mathrm{M}$ & Y \\
\hline Bending rear axle & 1 st $0 \mathrm{M}$ & $Y$ \\
\hline Static crash front & 1st OM / WE & - \\
\hline Static crash rear & 1st OM / WE & - \\
\hline Static crash side & 1st OM / WE & - \\
\hline
\end{tabular}

The calculative forces of driving conditions considered the dynamic behavior (Table 2) with the additional coefficients [37]. The final values were then applied to the attached points of the vehicle suspension. The authors of this work employed a work-energy balance approach [37] that determines the acting forces for the equivalent static crash loads. Additionally, we calculated the forces for the bending and torsion load cases [38] by performing the FE analyses for the current tubular space-frame. Furthermore, to assess the behavior of the vehicle during the accidents [38], we performed the virtual crash simulations on the complete FE eQuad model.

The FE model preparation for the TO contained a domain definition that allows the load paths to be generated using 3D FE mesh. This volume was limited by the available space for a new structure as well as by the vehicle equipment, which is attached to the vehicle structure.

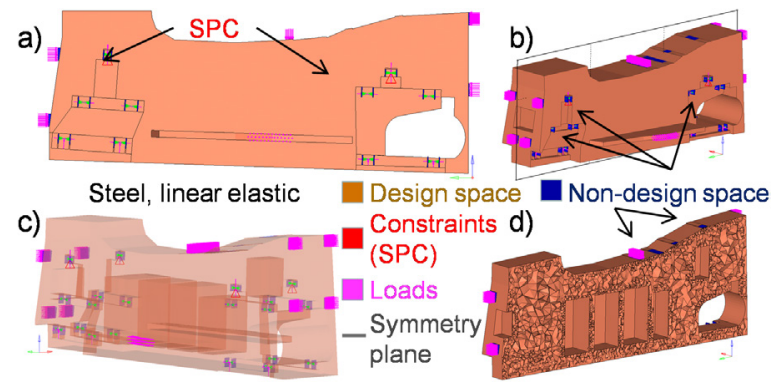

Fig. 10. Full FE model for the TO: a) \& b) 13 load cases, c) transparent view, d) cross-sectional view 
Therefore, the holes, cut-outs and geometric parts characterized the non-design space of the FE model that Fig. 10 exemplifies. Fig. 10 also presents the loads (forces) and constraints for the 13 load cases. The material model MAT1 was applied for the description of linear, temperature-independent, isotropic material properties that models the optimization domain, which was made of steel.

We employed an inertia relief approach that serves to increase optimization convergence and improve simulation stability in the case of unconstrained structures [29]. In addition, this FE model incorporated the minimum member size and longitudinal one plane symmetry that helps to regroup the elements in bigger accumulations and offers the option of obtaining symmetric material distribution even if the applied loads are asymmetric [29]. Fig. $10 \mathrm{~b}$ illustrates the longitudinal one plane symmetry option, which is depicted as a transparent longitudinal plane. This plane also provides the cross-section view of the FE model. The FE mesh consisted of the 3D tetra linear finite elements that can model complex geometric shapes.

The total initial mass of the FE model (Fig. 10) was $2111.9 \mathrm{~kg}$ for the first optimization run of each load case. The authors assumed that the maximal displacements of the optimized structure should not exceed the resultant value of $2 \mathrm{~mm}$ (in special cases, $3 \mathrm{~mm}$ ) for the selected load cases. The levels of volume fraction were set up for each load case (single or combined) to achieve the values of the established displacements. For the bending on the front and rear axles, the level of the volume fraction was adopted to the mean value of the other TO runs because of the larger displacements that provoked these load cases.

The limits on the maximum stresses were inconvenient to apply due to numerical obstacles that result from the change in the densities and Young's modulus for each finite element during the TO. Instead, the compliance minimization offers repeatable and stable distribution of the load paths.

\section{CONCEPTUAL DESIGN PHASE - RESULTS AND DISCUSSION}

The calculation results presented in this section correspond to the information about the methodology and models from the previous section. Additionally, the results are accompanied by comments. Furthermore, the quick FE reanalysis of a derivative geometric solution is illustrated at the end of this section.

\subsection{Understanding the TO Results}

We examined the methodology of the TO by performing the calculation for the basic examples presented in the previous sections as well as for the real use case (eQuad).

\subsubsection{Generalization of the TO Results - 2D Plate \& New eQuad Design}

Fig. 5 and 6 exhibit the generalization of the TO results. In addition, Table 1 reports on the maximal displacements that result in the TO. The results of five different material types demonstrate the same geometric contour. Only the geometry of the crossply laminate reveals a slightly different shape, but it follows the main lines of the common form. More importantly, the orientation of the stress tensor depicts the geometric contour of the common form. This observation affirms that the TO highlights the load path distributions. In other words, the load path distribution illustrates the lines of force flows in the whole structure that connect the points of force applications with the support areas.

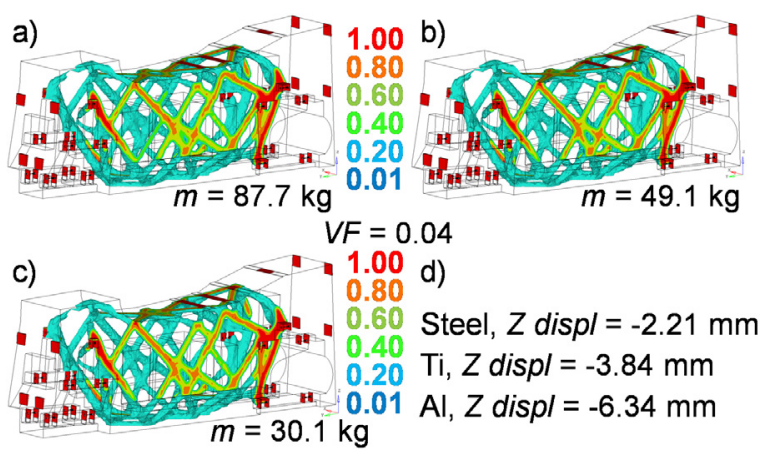

Fig. 11. TO for the vertical bump rear load: a) steel, b) titanium, c) aluminum, d) $Z$ displacements

The paper's authors also examined the generalization of the TO results for a real use case that contains the $3 \mathrm{D}$ mesh. The TO is now available for composite material types; however, it is inconvenient for 3D volume mesh due to the orientation of material principle axes, which define the properties of orthotropic material during optimization runs. The search for the optimal orientation of material principle axes aggravates the optimization process notably. On the other hand, the generalization of the TO results overcomes this obstacle successfully. For this reason, the authors also investigated the generalization of the TO results for the 3D mesh of the real use case. Fig. 11 presents the element densities and material 
distribution as well as the geometric shapes for three different material types: steel, titanium and aluminum. The minor changes in the geometric shapes result for the steel structure. The titanium and aluminum structures approximate the same geometric contour. Consequently, these facts proved the generalization of the TO results.

\subsection{2 " $\mathrm{X}$ " Cross Member as a Shear Element - 2D Plate}

Fig. 7 demonstrates the investigation of the " $\mathrm{X}$ " cross member formation. Changing the level of the volume fraction, the TO generally forms the same shapes as " $X$ " cross members, in which the tensor plot of original geometry (Fig. 7b) is recognizable. Compared to this case, the real case discloses any fully detailed piece of information that characterizes the acting loads (due to the combined load cases, which provoke the complicated stress states) at the fragment of the structure. Therefore, the " $\mathrm{X}$ " cross members can be recognized as the element that the shear field provokes. In consequence, the translation of the " $\mathrm{X}$ " cross members into the " $\mathrm{X}$ " shape of rods or thin plates depends on the designers' interpretations.

\subsection{Modern Lightweight Design: TO for a New eQuad Structure}

The TO results for a new eQuad structure illustrate the methodology highlighted in the previous sections. This methodology was applied to reveal the advantages of the first ICDDP design phase for the real use case.

\subsubsection{Separate vs. Combined Load Case Calculations and Multiple Run Approach}

We investigated the assessment of load case influences and the multiple run approach in the real use case by performing the TO for the 13 separate load cases. We applied the multiple run approach twice.

Table 3 makes evident the mass values at the end of each optimization run as well as the maximum displacements at the end of the second run. Owing to the limited space of this work, Figs. 12 and 13 present only the two single load cases: bending and static crash rear. The assessment of load case influences demonstrated the significance of each single load case more accurately.

Considering single load case separately, the behavior of applied loads is easier to capture. Consequently, the material distribution generates the clearer load paths that display the necessary members of a new structure. These pieces of information facilitate the phase of the geometric solution derivation.

Table 3. TO for the single load cases

\begin{tabular}{lccc}
\hline Load case & $\mathrm{ml}[\mathrm{kg}]$ & $\mathrm{mll}[\mathrm{kg}]$ & Max of displ [mm] \\
\hline Bending & 66.6 & 17.1 & $\mathrm{Z} /-1.365$ \\
\hline Torsion front & 66.6 & 29.7 & $\mathrm{Z} / 1.072$ \\
\hline Torsion rear & 71.8 & 38.6 & $\mathrm{Z} / 1.038$ \\
\hline Braking & 66.6 & 29.2 & $\mathrm{Y} / 1.540$ \\
\hline Braking into rear & 66.6 & 27.3 & $\mathrm{Y} /-1.747$ \\
\hline Cornering & 66.6 & 26.7 & $\mathrm{X} /-1.223$ \\
\hline Vertical bump front & 87.7 & 51.1 & $\mathrm{Z} /-1.823$ \\
\hline Vertical bump rear & 119.3 & 75.4 & $\mathrm{Z} /-1.549$ \\
\hline Bending front axle & 66.6 & 32.1 & $\mathrm{Z} / 14.12$ \\
\hline Bending rear axle & 66.6 & 36.7 & $\mathrm{Z} / 20.52$ \\
\hline Static crash front & 66.6 & 25.9 & $\mathrm{Y} /-1.853$ \\
\hline Static crash rear & 66.6 & 22.7 & $\mathrm{Y} / 1.823$ \\
\hline Static crash side & 66.6 & 49.6 & $\mathrm{Y} / 1.866$ \\
\hline ml, mll - mass after 1st and 2nd T0 runs, respectively; \\
\hline
\end{tabular}

a)
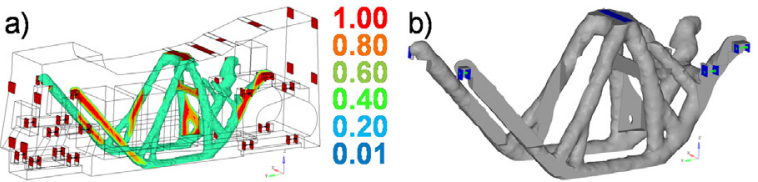

c)

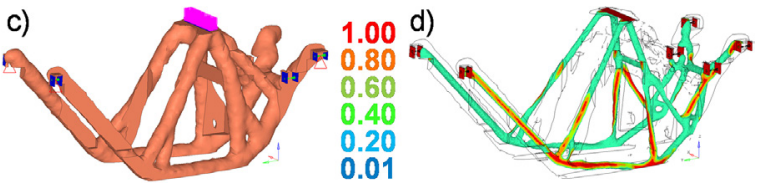

Fig. 12. T0 results of the bending: a) element densities at 1st run, b) geometry extraction of FE model at $2^{\text {nd }}$ run, c) 0SSmooth geometry at $2^{\text {nd }}$ run, d) element densities at $2^{\text {nd }}$ run

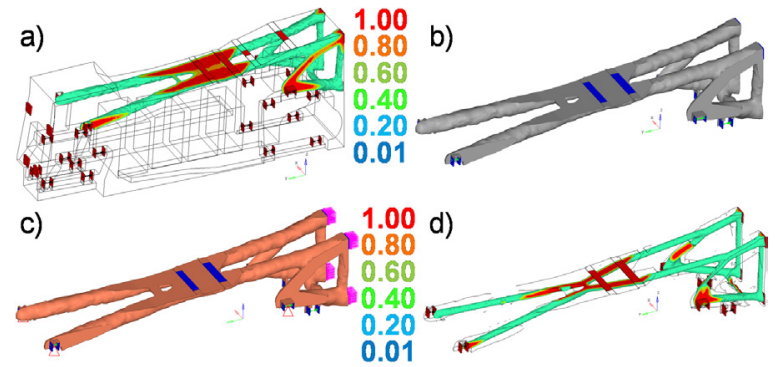

Fig. 13. TO results of the static crash rear: a) element densities at 1st run, b) geometry extraction of FE model at $2^{\text {nd }}$ run,

c) OSSmooth geometry at $2^{\text {nd }}$ run, d) element densities at $2^{\text {nd }}$ run

Figs. 12 and 13 exemplify the benefits of the multiple run approach. The dominance of intermediate values is pointed out in the element density plots of the first runs (Figs. 12a and 13a). The element density plots should intentionally present a contrast picture with the values of element density close to 1 for the major elements. The thickness of the single 
structural members in the second TO run decreased, leading to the elements of the greater density level becoming more noticeable (Figs. 12d and 13d). Even though the second TO run reduced the remaining mass significantly, where the reduction was more than $70 \%$ in some cases (Table 3), the stiffer elements (density near 1) were difficult to notice due to the allocation of such elements on the center lines of the geometric shapes.

More importantly, Figs. 14 and 15 affirm that the multiple run approach works properly for the combined load case by reducing the overall structural weight. Compared to the TO run of the single load cases, the paper's authors applied the TO to the combined load case three times.

Table 4. TO for the combined load case

\begin{tabular}{|c|c|c|c|c|}
\hline $\begin{array}{l}\text { Load } \\
\text { case }\end{array}$ & $\begin{array}{c}\mathrm{ml} \\
{[\mathrm{kg}]}\end{array}$ & $\begin{array}{l}\mathrm{mll} \\
{[\mathrm{kg}]}\end{array}$ & $\begin{array}{l}\mathrm{mlll} \\
{[\mathrm{kg}]}\end{array}$ & $\begin{array}{l}\text { Max of displ } \\
{[\mathrm{mm}]}\end{array}$ \\
\hline CLC & 214 & 150.6 & 94 & $Z 8=-2.897 / Y 12=1.312$ \\
\hline \multicolumn{5}{|c|}{$\begin{array}{l}\text { CLC - combined load case; } \mathrm{ml}, \mathrm{mll}, \mathrm{mIll} \text { - mass after } 1 \text { st, } 2^{\text {nd }} \text { and } \\
3^{\text {rd }} \text { optimization runs, respectively; } Z 8 \text { - Z displacement for vertical } \\
\text { bump rear case; } Y 12 \text { - Y displacement for static crash rear case; }\end{array}$} \\
\hline
\end{tabular}

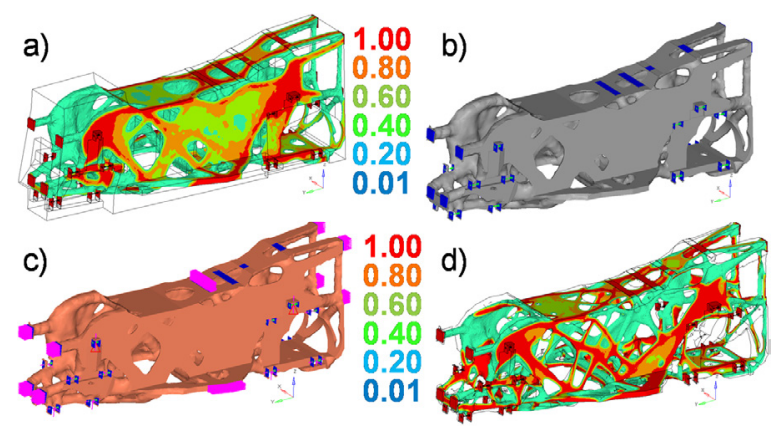

Fig. 14. TO results of the combined loads case: a) 1st run, b) geometry extraction, c) 2nd run, d) 2nd run

The material distributions became more discrete passing from one optimization run to the other. Additionally, Figs. 14 and 15 illustrate the areas that correspond to some plate-like shapes. The surface of such areas decreased with the steps of the multiple run method. Similarly, the element densities contrasted the dominance of higher values (Fig. 14d and 15d) that were close for the most part to 1.0.

The results of the multiple run approach revealed the distributions of the material and load paths that indicate fundamental geometric shapes of a new structure (Fig. 15d). The elements of the great density levels (near 1) highlighted the zones that actually require the material. Such polarized distributions allow for the geometric solution derivation. In addition, Table 4 illustrates the mass levels at the end of each TO run and the resultant displacement of the third run for the vertical bump rear load, which was used as the soft constraint throughout these three runs.

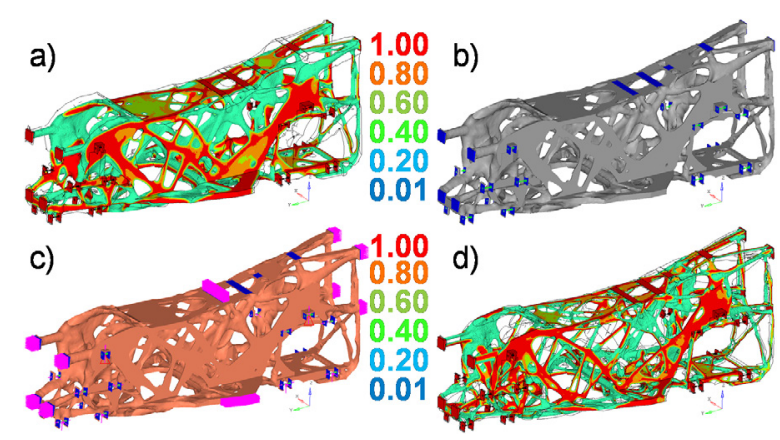

Fig. 15. T0 results of the combined loads case: a) 2nd run, b) geometry extraction, c) 3rd run, d) 3rd run

The resultant displacement of the static crash rear loads is smaller due to the more complete outline of a new structure. Although the multiple run approach influenced the significant mass reduction, the end mass value of $94 \mathrm{~kg}$ is more than the mass of $82 \mathrm{~kg}$ for the original tubular space frame (Fig. 9b). The additional requirements for a new structure, i.e. crashworthiness, prompted the addition of weight to the TO results. For this reason, the paper's authors investigated the influence of the crash loads over the resultant geometry of a new structure.

\subsubsection{Influence of Crash Loads}

We carried out the TO runs, which included the application of the multiple run approach three times, to display the effect of crash loads on a new structure. The investigative load case consisted of all combined load cases without the crash loads. Fig. 16 demonstrates that the geometric shapes differ markedly for each step of the multiple run approach, compared with the results in Figs. 14 and 15.

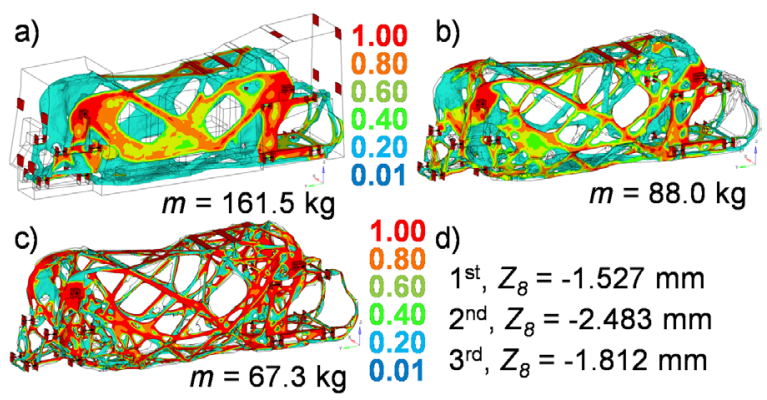

Fig. 16. TO for the influence of crash loads: a) 1st run, b) 2nd run, c) 3 rd run, d) Z displacements 
The lack of geometric shapes, which are characteristic for the crash loads, is exhibited in the front, lower central and rear parts of a new structure. Consequently, the mass levels in each of the TO runs were considerably lower than they were in the case of all combined loads.

\subsubsection{Geometric Solution Derivation}

We conducted the geometric solution derivation to express the fundamental manufacturable geometry from the TO results. We assumed that the distribution of material and load paths together with the knowledge of applied loads define the characteristics of acting loads, thus resulting in the bionic shapes of a new geometry.

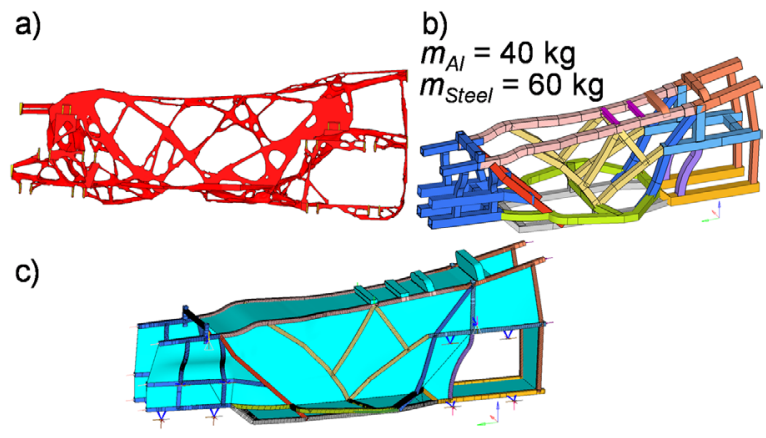

Fig. 17. Geometric solution derivation: a) bionic 00Smooth geometry, b) CAD / FEM model interpretation, c) FE model for design crystallization

Table 5. FEA for the $1 D$ beam model - maximum of the resultant displacements

\begin{tabular}{lcc}
\hline Load case & Aluminum, $[\mathrm{mm}]$ & Steel, $[\mathrm{mm}]$ \\
\hline Bending & $\mathrm{Z} /-1.234$ & $\mathrm{Z} /-0.700$ \\
\hline Torsion front & $\mathrm{Z} / 1.428$ & $\mathrm{Z} / 0.813$ \\
\hline Torsion rear & $\mathrm{Z} / 1.703$ & $\mathrm{Z} / 0.977$ \\
\hline Braking & $\mathrm{Y} / 0.644$ & $\mathrm{Y} / 0.378$ \\
\hline Braking into rear & $\mathrm{Y} /-0.959$ & $\mathrm{Y} /-0.564$ \\
\hline Cornering & $\mathrm{X} /-3.476$ & $\mathrm{X} /-6.082$ \\
\hline Vertical bump front & $\mathrm{Z} /-2.826$ & $\mathrm{Z} /-1.617$ \\
\hline Vertical bump rear & $\mathrm{Z} /-3.852$ & $\mathrm{Z} /-2.231$ \\
\hline Bending front axle & $\mathrm{Z} / 9.287$ & $\mathrm{Z} / 5.458$ \\
\hline Bending rear axle & $\mathrm{Z} / 51.350$ & $\mathrm{Z} / 29.490$ \\
\hline Static crash front & $\mathrm{Y} /-1.000$ & $\mathrm{Y} /-0.594$ \\
\hline Static crash rear & $\mathrm{Y} / 1.150$ & $\mathrm{Y} / 0.691$ \\
\hline Static crash side & $\mathrm{Y} / 15.130$ & $\mathrm{Y} / 8.698$ \\
\hline $\begin{array}{l}\text { Wall thickness of rectangular cross-sections: steel }-2 \mathrm{~mm},-4 \mathrm{~mm} ; \\
\text { Various dimensions of rectangular cross-sections for selected } \\
\text { profiles }\end{array}$
\end{tabular}

The geometric solution derivation is based on the rod-like and plate-like geometric elements that form the bionic shapes of a new structure. Fig. 17 illustrates the geometry interpretation in the OSSmooth $^{\circledR}$ software (Fig. 17a) as well as the rough design of a new structure - space frame (Fig. 17b).

We achieved the final design in CAD software by following the main lines of the load paths and using the industrial rectangular hollow profiles [39] and [40]. These profiles of the cross-sections had four different dimensions: $25 \mathrm{~mm} \times 25 \mathrm{~mm}, 35 \mathrm{~mm} \times 35 \mathrm{~mm}, 40$ $\mathrm{mm} \times 40$ and $50 \mathrm{~mm} \times 50 \mathrm{~mm}$ for both steel and material types.

The goal of the quasi-static FEA was to establish how much lightweight potential the first rough design of a new structure has. For this reason, we conducted the FEA for all 13 load cases and two material types: steel and aluminum. Table 5 shows the FEA results for the 1D FE model. The displacements calculated are comparable to or lower (Tables 3 and 5) than the rough results from the TO runs and affirm the conceptual design phase. Consequently, the derived simple spaceframe has great lightweight potential.

As a summary of the ICDDP's design advantages, Fig. 18 affirms the great mass reductions while applying the ICDDP to the new structure design.

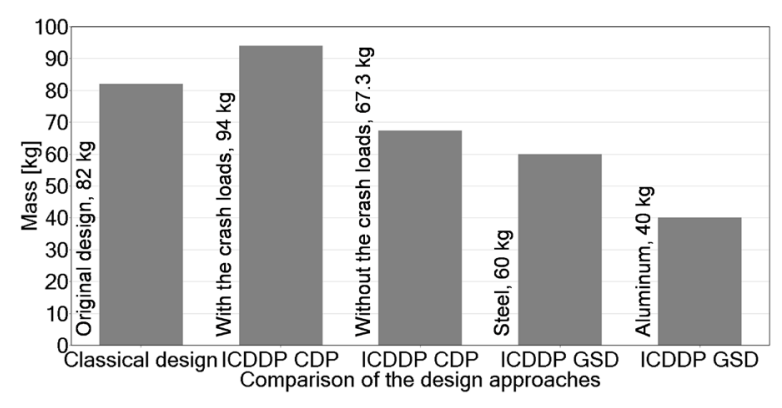

Fig. 18. Comparison of the design approaches

Compared to the design approach (original design), the conceptual design phase of the ICDDP (Fig. 18, ICDDP CDP) delivers significantly lighter solutions (in the case without the crash loads). The original design of the eQuad structure neglected the crash loads, whereas the new design of the eQuad structure, which also considers the crash loads, results from the first phase of the ICDDP with a higher mass $(94 \mathrm{~kg})$ than the original design $(82 \mathrm{~kg})$; yet, the geometric solution derivation step asserts that the first phase of the ICDDP provides the valuable design suggestions with its notable lightweight design (Fig. 18, ICDDP GSD for steel $60 \mathrm{~kg}$ and aluminum $40 \mathrm{~kg}$ ). The ICDDP produces the efficient design concepts that meet the given sets of different requirements, including the crash loads. 


\section{CONCLUSIONS}

Over the past decade, the mechanical engineering industry has been searching for an approach to the design process that integrates $\mathrm{CAE}$ tools and helps to develop innovative and competitive products. For this reason, we established the ICDDP as the design process that is driven by the optimization technology. Our definition of the ICDDP offers the stable and repeatable framework for engineers and designers that can create a new product in the various divisions of the mechanical engineering sector. More importantly, our description of the ICDDP ensures reductions in working time, user-friendly orientation and efficient resource management.

Consequently, we tested the conceptual design phase of the ICCDP for a real use case - a new eQuad structure. Since a body structure is fundamental to vehicle integrity, a new structure needs an accurate, innovative and lightweight design. On account of the fact that the new conceptual structure of the eQuad reveals these design properties, the conceptual design phase of the ICDDP fulfills the promises of a suitable, reliable and innovative tool.

Once the rough lightweight design of the new structure is obtained, this structure requires that additional design crystallization (the second phase of the ICDDP) take full advantage of weight reduction. The discussion of body-in-white structure types is a fundamental step for this phase. Such a discussion explores the 1D \& 2D FE model (Fig. 17c), which is the improvement to the FE model from the geometric solution derivation step.

The design crystallization phase is under intensive ongoing scientific investigation that integrates the fundamental elements of a vehicle body design and different material types such as composites and sandwich composites. The first results of the design crystallization phase suggest utilizing these simple FE models for further design and structure determination.

\section{ACKNOWLEDGEMENTS}

This work was accomplished at the VIRTUAL VEHICLE Research Center in Graz, Austria. The authors would like to acknowledge the financial support of the COMET K2 - Competence Centers for Excellent Technologies Program of the Austrian Federal Ministry for Transport, Innovation and Technology (BMVIT), the Austrian Federal Ministry of Science, Research and Economy (BMWFW), the Austrian Research Promotion Agency (FFG), the
Province of Styria and the Styrian Business Promotion Agency (SFG).

\section{REFERENCES}

[1] Sellgren, U. (1999). Simulation-Driven Design - Motives, Means, and Opportunities. PhD thesis. KTH, Stockholm.

[2] Sjödin, T. (2010). Optimization-driven design at Saab automobile AB. ProOpt Workshop on Optimization Driven Design Proceedings, Jönköping.

[3] Konzelmann, M., Krishnamoorthy, S., Chaudhari, S., Kopp, G., Friedrich, H.E. (2013). CAE-driven design methodology for semi-autonomous product development. European Altair Technology Conference Proceedings, Torino.

[4] Münster, M., Schäffer, M., Friedrich, H.E. (2015). Development of body structure concepts for electric vehicles using the topology optimization for global load pathfinding. European Altair Technology Conference Proceedings, Paris.

[5] Kramer, F. (1986). Innovative Produktpolitik, Strategie - Planung - Entwicklung - Einführung. Springer, Berlin, DOI:10.1007/978-3-642-95504-4. (in German)

[6] Vanja, S., Weber, C., Bley. H., Zeman, K., Hehenberger, P. (2009). CAx für Ingenieure. Springer, Berlin Heidelberg, Dol:10.1007/978-3-540-36039-1. (in German)

[7] Henkel, N., Treiber S. (2015). Cost-effective sizing of your HPC cluster for CAE simulations. 10 th European LS-DYNA Conference Proceedings, Würzburg.

[8] Gupta, S.K., Anand, D.K., Brough, J.E., Schwartz, M., Kavetsky, R.A. (2008). Training in Virtual Environments. A Safe, CostEffective, and Engaging Approach to Training. University of Maryland, Maryland.

[9] Leadley-Brown, M. (2011). Simulation driven design. Deutsche SIMULIA-Konferenz Proceedings, Bamberg.

[10] Von Dungern, O., Hoffmann, R. (2016). Using knowledge graphs for automotive safety requirements management. 9th Graz Symposium Virtuelles Fahrzeug Proceedings, Graz.

[11] Kompas, K., Wang, L., Jung, O. (2016). Effectiveness assessment of future vehicle safety systems. 9th Graz Symposium Virtuelles Fahrzeug Proceedings, Graz.

[12] Merklein, M., Geiger, M. (2002). New materials and production technologies for innovative lightweight constructions. Journal of Materials Processing Technology, vol. 125-126, p. 532536, D0I:10.1016/S0924-0136(02)00312-6.

[13] Thomas, D., Block, H., Tröster, T. (2011). Production of load-adapted lightweight designs by partial hardening. 3rd International Conference on Steel in Cars and Trucks Proceedings.

[14] Iljaž, J., Škerget, L., Štrakl, M., Marn, J., (2016). Optimization of SAE formula rear wing. Strojniški vestnik - Journal of Mechanical Engineering, vol. 62, no. 5, p. 263-272, DOl:10.5545/sv-jme.2016.3240.

[15] Cesnik, M., Slavic, J., Boltežar, M., (2016). Assessment of the fatigue parameters from random vibration testing: application to a rivet joint. Strojniški vestnik - Journal of Mechanical Engineering, vol. 62, no. 7-8, p. 471-482, D0l:10.5545/svjme.2016.3774. 
[16] Harzheim, L. (2014). Strukturoptimierung: Grundlagen und Anwendungen. 2 Auflage. Europa-Lehrmittel, Haan-Gruiten. (in German)

[17] Hirz, M., Dietrich, W., Gfrerrer, A., Lang, J. (2013). Integrated Computer-Aided Design in Automotive Development. SpringerVerlag, Berlin-Heidelberg, D0l:10.1007/978-3-642-11940-8.

[18] Stanton, M. (2015). Exceeding customer expectations by left shifting with robust virtual engineering at jaguar land rover. European Altair Technology Conference Proceedings, Paris.

[19] Kang, B. (2015). CAE for digital development. European Altair Technology Conference Proceedings, Paris.

[20] The Association of German Engineers (VDI) (1997). VDI 2221: Methodik zum Entwickeln und Konstruieren technischer Systeme und Produkte. Verein Deutscher Ingenieure, Düsseldorf. (in German)

[21] The Association of German Engineers (VDI) (1997). VDI 2222: Blatt 1 Methodisches Entwickeln von Lösungsprinzipien. Verein Deutscher Ingenieure, Düsseldorf. (in German)

[22] The Association of German Engineers (VDI) (1997). VDI 2223: Blatt 1 Methodisches Gestalten. Verein Deutscher Ingenieure, Düsseldorf. (in German)

[23] Ehrlenspiel, K. (2003). Integrierte Produktentwicklung. 2. Auflage. Hanser, München. (in German)

[24] Warnecke, U., Rosenplaenter, S. (2016). The Journey to MBSE and PLM. 9th Graz Symposium Virtuelles Fahrzeug Proceedings, Graz.

[25] C123. Altair Engineering, Inc, from http://www.altair.com/ newsdetail.aspx?news_id=11283, accessed on 2016-11-10.

[26] Jedrzejczyk, R.P., Alb, M., Jost, T. (2015). Optimierung als wesentlicher Punkt in der Leichtbau-Konzeptentwicklung. 4a Technologietage 2015 Proceedings, Schladming.

[27] Jedrzejczyk, R.P., Alb, M., Jost, T. (2015). Conceptual studies of the lightweight vehicle structure for the L7e vehicle class by the use of optimization process at OptiStruct environment. European Altair Technology Conference Proceedings, Paris.

[28] Jedrzejczyk, R.P., Alb, M., Jost, T. (2016). CAE-driven design process for modern lightweight structures. 9th Graz Symposium Virtuelles Fahrzeug Proceedings, Graz.

[29] Altair Engineering Inc. (2015). HyperWorks 14.0. OptiStruct Reference Guide, Melbourne.
[30] Altair Engineering Inc. (2015). HyperWorks 14.0. OptiStruct User's Guide, Melbourne.

[31] Soden, P.D., Hinton, M.J., Kaddour, A.S. (1998). Lamina properties, lay-up configurations for a range of fibrereinforced composite laminates. Composites Science and Technology, vol. 58, no. 7, p. 1011-1022, D0l:10.1016/S02663538(98)00078-5.

[32] Daniel, M.I., Ishai, 0. (2006). Engineering Mechanics of Composite Materials. 2nd Edition. Oxford University Press, New York, Oxford.

[33] Norberg, E., Lövgren, S. (2011). Topology Optimization of Vehicle Body Structure for Improved Ride \& Handling. MSc thesis. Linköping University, Linköping.

[34] eQuad. Virtual Vehicle Research Center, from http://www. v2c2.at/en/research/ee-and-software/projects/equad/, accessed on 2016-11-10.

[35] Edwards, M., Seidl, M., Carroll, J., Nathanson, A. (2014). Provision of information and services to perform an initial assessment of additional functional safety and vehicle construction requirements for $L 7 e-A$ heavy on-road quads. Transport Research Laboratory. European Commission, Brussels.

[36] Krishnamoorthy, S.K., Beeh, E., Schöll, R., Friedrich, H.E. (2012). Methodik zur Karosserieentwicklung mittels Topologieoptimierung. Tagung Faszination Karosserie und Fahrzeugkonzepte Proceedings. Wolfsburg. (in German)

[37] Malen, D.E. (2011). Fundamentals of Automobile Body Structure Design. SAE International, Warrendale.

[38] Jedrzejczyk, R.P., Jost, T. (2015). The finite element assessment of structure properties for a L7e class vehicle under the bending, torsion static and crash loads. ICOEV 2015 International Conference on Engineering Vibration Proceedings, Ljubljana.

[39] Metric Rectangular Tube. Parker Steel Company, from http:// www.metricmetal.com/products/rec2395.htm, accessed on 2016-11-10.

[40] Parker Steel Company. (2016). Metric Size Metals. Metric Metals Reference Guide, Toledo. 